\title{
Febril Konvülziyon Hakkında Hasta Yakınlarının Bilgi, Kaygı ve Düşünceleri
}

\section{Knowledge, Concern and Thoughts of Patient Relatives about Febrile Convulsions}

\author{
Gökçen ÖZ TUNÇER ${ }^{1}$, Dilşa Cemre AKKOÇ², Pelin ALBAYRAK ${ }^{1}$, Muhammed Gültekin KUTLUK로 \\ Serap TEBER ${ }^{1}$, Gülhis DEDA ${ }^{1}$
}

1Ankara Üniversitesi Tıp Fakültesi, Çocuk Sağlığı ve Hastalıkları Anabilim Dalı, Çocuk Nörolojisi Bilim Dalı, Ankara, Türkiye

${ }^{2}$ Ankara Üniversitesi Tıp Fakültesi, Çocuk Sağlığı ve Hastalıkları Anabilim Dalı, Ankara, Türkiye

Öz

Amaç: Hastanemize herhangi bir nedenle başvuran hastaların yakınlarının febril konvülziyon hakkındaki bilgi, kaygı ve düşünceleri değerlendirilmesi amaçlanmıştır.

Gereç ve Yöntemler: Çalışmaya 18-70 yaş arası 600 katıımcı alındı. Katılımcıların yaş, eğitim ve gelir seviyesi, febril konvülziyon hakkındaki bilgileri ve bilgi kaynakları, kaygı durumları sorgulandı.

Bulgular: Üç yüz seksen iki katılımcı (\%63.6) febril konvülziyonun ne olduğunu bildiğini beyan etmekle beraber sadece 101 (\%16.8) katıımcının tanımlaması doğruydu. Benzer şekilde febril konvülziyon geçiren çocuğa nasıl müdahale edeceğini bildiğini söyleyen 337(\%56.2) kişinin ancak 31'inin (\%5.1) bilgisi doğruydu. Eğitim ve gelir düzeyi arttıkça febril konvülziyon ve febril konvülziyona nası müdahale edileceği hakkındaki bilgi de artmaktaydı. 227 (\%37.8) katıımcının bir yakını febril konvülziyon geçirmişti, 211 (\%35.2) katıımcı ise bizzat febril konvülziyona tanıklık etmişti ve tanıklık edenlerin \%80'i kaygılanmıștı. Febril konvülziyona tanıklık etmek ve müdahale konusundaki bilginin doğruluğu arasında pozitif korelasyon mevcuttu. Yine katıımcının bir yakını febril konvülziyon geçirdi ise nasıl müdahale edeceği ile ilgili bilgisi artmıştı. 449 (\%74.8) katıımcı febril konvülziyonun kalıcı bir hasar bıraktığını düşünüyordu.

Sonuç: Febril konvülziyon sağlık çalışanları için sık karşılaşılan benign bir klinik tablo olsa da ilk defa şahit olan hasta yakınları için çok ürkütücü olabilir. Katılımcıların febril konvülziyon hakkındaki bilgi düzeyi belirgin düşük, kaygıları ise yüksek saptandı. Hasta yakınlarının sağlık çalışanları tarafından eğitimi faydalı olacaktır.

Anahtar Sözcükler: Bilgi Düzeyi, Febril konvülziyon,Kaygı

\begin{abstract}
Objective: The aim was to evaluate the knowledge, concerns and thoughts about febrile convulsions of patient relatives attending our hospital for any reason.

Material and Methods: The study included 600 participants aged from 18-70 years. The participants were questioned about age, educational and income levels, knowledge and sources of knowledge about febrile convulsions and level of concern.

Çıkar Çatıșması / Conflict of Interest: Tüm yazarlar adına, sorumlu yazar çıkar çatıșması olmadığını belirtir.

Etik Kurul Onayı / Ethics Committee Approval: Bu çalıșmada ulusal ve uluslararası etik kurallara uyulmuștur. Çalıșma için Akademik kurul karar no: 69545805 050.01.04/E.27071 ile onay alınmıștır.

Yazarların katkısı / Contribution of the Authors: ÖZ TUNCER G: Araştırma ve/veya makalenin hipotezini veya fikrini oluşturan, Sonuçlara ulaşmak için planlama/ metodoloji belirleme, Araștırma/çalıșmanın sorumluluğunu üstlenmek, ilerlemenin seyrini denetlemek, Hasta takibinde sorumluluk almak, ilgili biyolojik malzemeleri toplanması, veri yönetimi ve raporlama, deneylerin yürütülmesi, Sonuçların mantıksal olarak Yorumlanması ve sonuç̧landırılması, Çalıșma için gerekli literatü taramasında sorumluluk almak, Çalıșmanın bütününün veya önemli bölümlerinin yazımında sorumluluk almak, Yazım ve dilbilgisi dıșında bilimsel olarak gönderilmeden önce makaleyi gözden geçirme. AKKOC DC: Arastırma ve/veya makalenin hipotezini veya fikrini olușturan, Sonuçlara ulașmak için planlama/metodoloii belirleme, ve raporlama deneylerin yürütülmesi, Sonucların mantıksal olarak Yorumlanması ve sonuclandirlma Çalıșmanın bütününün veya önemli bölümlerinin yazımında sorumluluk almak, Yazım ve dilbilgisi dışında bilimsel olarak gönderilmeden önce makaleyi gözden geçirme. ALBAYRAK P: Sonuçların mantıksal olarak Yorumlanması ve sonuçlandıııması, Çalısma için gerekli literatür taramasında sorumluluk almak, Çalışmanın bütününün veya önemli bölümlerinin yazımında sorumluluk almak, Yazım ve dilbilgisi dıșinda bilimsel olarak gönderilmeden önce makaleyi gözden geçirme. KUTLUK $\boldsymbol{M G}$ Sonuçların mantıksal olarak Yorumlanması ve sonuçlandırılması, Çalıșma için gerekli literatür taramasında sorumluluk almak, Yazım ve dilbilgisi dıșında bilimsel olarak gönderilmeden önce makaleyi gözden geçirme. TEBER S: Sonuçların mantıksal olarak Yorumlanması ve sonuçlandırılması, Çalıșma için gerekli literatür taramasında

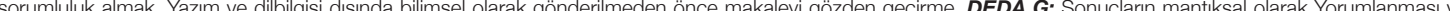
sonuçlandırıması, Çalıșma için gerekli literatür taramasında sorumluluk almak, Yazım ve dilbilgisi dıșında bilimsel olarak gönderilmeden önce makaleyi gözden geçirme. Atıf yazım şekli / How to cite : Öz Tuncer G, Akkoç DC, Albayrak P, Kutluk MG, Teber S, Deda G. Knowledge, Concern and Thoughts of Patient Relatives about Febrile Convulsions. Turkiye Cocuk Hast Derg 2021; 15: 19-23.
\end{abstract}

ÖZ TUNCER G: 0000-0002-4027-6330 AKKOÇ DC : :0000-0001-5172-3303 ALBAYRAK P : 0000-0001-8796-1493 KUTLUK MG : 0000-0002-3631-068X TEBER S DERA
Yazışma Adresi / Correspondence Address:

Gökçen ÖZ TUNÇER

Ankara Üniversitesi Tıp Fakültesi, Çocuk Sağlığı ve Hastalıkları Anabilim Dalı,

Cocuk Nörolojisi Bilim Dalı, Ankara, Türkiye

E-posta: gokcenoz@hotmail.com
Geliş tarihi / Received : 02.08.2019 Kabul tarihi / Accepted : 02.12.2019 Elektronik yayın tarihi : 13.04 .2020 Online published

DOI: 10.12956/tchd.600239 
Results: While 382 participants (63.6\%) stated they knew what febrile convulsion was, only 101 participants (16.8\%) gave an accurate description. Similarly, 337 people (56.2\%) said they knew how to intervene with a child experiencing febrile convulsion, but only 31 (5.1\%) had accurate information. As education and income levels increased, knowledge about febrile convulsion and how to intervene increased. For 227 participants (37.8\%), a member of their family had experienced febrile convulsion, while 211 (35.2\%) of participants had witnessed febrile convulsion and $80 \%$ of those who witnessed it were concerned. There was a positive correlation between witnessing febrile convulsion and accuracy of information about intervention. In addition, if a relative of the participant had experienced febrile convulsion, knowledge about how to intervene increased. A total of 449 participants (74.8\%) thought that febrile convulsion involved permanent injury.

Conclusion: Though febrile convulsion is a commonly encountered benign tableau for health workers, it may be very frightening for a patient relative witnessing it for the first time. Participants were identified to have clearly low levels of knowledge about febrile convulsion and high levels of concern. It will be beneficial for health workers to educate patient relatives.

Key Words: Knowledge, Febrile convulsion, Anxiety

\section{Giriş}

Febril konvülziyon (FK) nöbeti tetikleyen başka bir faktör ve afebril nöbet öyküsü olmaksızın 6 ay ile 5 yaş arasında, $38^{\circ} \mathrm{C}$ üzerinde ateş ile görülen çocukluk çağındaki en sık nöbet nedenidir (1,2). 24 saat içinde 1 defa görülen, jeneralize vasıflı 15 dakikadan kısa süren FK'lar basit olarak adlandırırken, fokal, 15 dakika süreli ya da 24 saat içerisinde tekrar eden FK'lar komplike olarak tanımlanır (3). FK'ların \% 70-75'i basit, \%20-25'i komplikedir (4). Benign prognozuna rağmen hasta yakınlarını çok endişelendirmekte olup acil servislere en sık başvuru nedenlerinden biridir. Şahit olan çoğu ebeveyn kalıı bir hasardan hatta çocuklarının öleceğinden endişe edebilmektedir. Bilgi yetersizliği ve yardım edemeyecek olma hissi ailelerin endişelerini perçinlemektedir. Bu durum ilk FK'dan sonra aylarca devam edebilir (6). Bu çalsşmada hastanemize herhangi bir nedenle başvuran hasta yakınlarııı FK hakkındaki bilgi, kaygı ve düşünceleri değerlendirilmiştir.

\section{GEREÇ ve YÖNTEMLER}

Anket çalışması Eylül - Aralık 2017 tarihleri arasında yapıldı (Akademik kurul karar no: 69545805-050.01.04/E.27071). Araştırma katılımcı sayısı 600 olarak belirlendi. Herhangi bir sebep ile çocuk polikliniklerine başvuran hastalarına refakat eden 18-70 yaş arası hasta yakınları anket çalışmasına katımaya rastgele davet edildi. Kabul edip sözlü onam alınan 600 anonim hasta yakınına araştıııılar tarafından anket uyguladı. Anket soruları katılımcıların demografik bilgilerini, eğitim seviyelerini, gelir düzeylerini, ateş ve ateşli havale ile ilgili bilgilerini, bilgi kaynaklarını sorgulamaktaydı. 2017 yılındaki asgari ücret (1500 TL) baz alınarak gelir düzeyi asgari ücretin katları şeklinde dörde ayrıldı. Ateşli havale hakkında katıımcıların bilgi sahibi olup olmadıkları soruldu, bilgi sahibi olduklarını beyan edenlere ise açık uçlu olarak ne bildikleri soruldu ve verilen cevaplara göre bilgilerin doğruluğu araştırmacılar tarafindan denetlendi. Doğru yaş aralığı ve santral sinir sistemi dışı enfeksiyon nedeni yüksek ateş ile havale tanımı doğru kabul edildi. Müdahale için ise kurtarma pozisyonunu tarifini içeren cevaplar doğru kabul edildi, onun dışında kalan çocuğu sarsmak, ağzını cisimle açmaya çalışmak, yüzünü / vücudunu suya sokmak, yüzüne su serpmek, konvülziyon esnasında ateş düşürücü / su içirmeye çalışmak gibi davranışlar yanlış kabul edildi.

Ayrıca katılımcların FK'a tanıklik edip etmedikleri, ettilerse kaygı duyup duymadıkları, yakınlarının FK geçirip geçirmediği değerlendirildi.

\section{İstatistiksel analiz:}

Çalışmamızdaki verilerin analizinde Statistical Package for the Social Sciences (SPSS) version 22 kullanıldı. Olgu sayısının belirlenmesi amacıly yapılan power analizinde, \%80 test gücünde ve 0.05 alfa katsayısında minumum olgu sayısı 489 olarak tespit edildi; olgu sayısı 600 olarak alındı. Verilerin gösteriminde hasta sayısı (n) ve persentil (\%) kullanıldı. Verilerin kendi içinde analizinde Pearson Kikare testi kullanıldı, $\mathrm{p}<0.05$ düzeyi anlamlı kabul edildi.

\section{BULGULAR}

Katılımcların 395'i (\% 65.8) kadın, 205'i (\%34.2) erkekti. Katılımcıların 534'ünün (\%89) çocuğu vardı. Yaş gruplarına ayrlınca ise \% 38.7'sinin 35-44 yaş arası olduğu görüldü (Tablo I). Hastaların eğitim seviyeleri ve gelir düzeyleri Tablo Il'de verildi.

Beş yüz üç katıımcının (\%83.8) evinde termometre bulunuyordu. 382 katılımcı (\%63.6) FK'un ne olduğunu bildiğini beyan etti, tanımlamaları istendiğinde ise 101 (\%16.8) katılımonın tanımlaması doğru bilgiler içermekteydi. Üç yüz seksen iki

Tablo I: Katılımcıların yaşa göre dağııımı.

\begin{tabular}{l|c}
\hline Yaş grubu (yıl) & $\mathbf{n}(\%)$ \\
\hline $\mathbf{1 8 - 2 4}$ & $55(\% 9.2)$ \\
$\mathbf{2 5 - 3 4}$ & $203(\% 33.8)$ \\
$\mathbf{3 5 - 4 4}$ & $232(\% 38.7)$ \\
$\mathbf{4 5 - 5 4}$ & $81(\% 13.5)$ \\
$\mathbf{5 5 - 6 4}$ & $23(3.8)$ \\
$\mathbf{6 5 +}$ & $6(\% 1)$ \\
\hline
\end{tabular}


Tablo II: Katılımcıların eğitim / gelir düzeyleri.

\begin{tabular}{lc}
\hline & $\mathbf{n} \%$ \\
\hline Eğitim Düzeyi & $4(\% 0.7)$ \\
Okur yazar değil & $5(\% 0.8)$ \\
Okur yazar & $103(\% 17.2)$ \\
İlkokul & $88(\% 14.7)$ \\
Ortaokul & $218(\% 36.3)$ \\
Lise & $156(\% 26)$ \\
Üniversite & $26(\% 4.3)$ \\
Master/doktora & \\
Gelir Düzeyi & $174(\% 29)$ \\
1500 tl ve altı & $220(\% 36.7)$ \\
$1500-3000$ tl & $124(20.7)$ \\
3000-4500 & $82(13.7)$ \\
4500 tl ve üzeri
\end{tabular}

Tablo III: Katıımcıların febril konvülziyona nasıl müdahale edecekleri hakkındaki bilgi kaynakları.

\begin{tabular}{l|cc}
\hline & $\begin{array}{l}\text { Febril konvülziyona müdahale etmeyi bildiklerini } \\
\text { belirten } \mathbf{3 3 7} \text { kişinin bilgi kaynakları }\end{array}$ & $\begin{array}{l}\text { Febril konvülziyona müdahale etmeyi bilen } \\
\text { 31 kişinin bilgi kaynakları }\end{array}$ \\
\hline Sağlık çalışanı & $148(\% 43.9)$ & $18(\% 58)$ \\
\hline Kitap & $52(\% 15.4)$ & $7(\% 22.6)$ \\
Kendi deneyimi & $142(\% 42.1)$ & $9(\% 29)$ \\
Etraftan duydukları & $149(\% 44.2)$ & $9(\% 29)$ \\
\hline İnternet & $97(\% 28.8)$ & $12(\% 38.7)$ \\
\hline TV & $59(\% 17)$ & $3(\% 9.7)$ \\
Gazete & $24(\% 7)$ & $2(\% 6.5)$ \\
\hline
\end{tabular}

Tablo IV: Katılımcıların febril konvülziyonun hangi kalıcı hasarı bıraktığı hususundaki görüşleri

Febril konvülziyon hangi kalıcı hasarı bırakır $(n=449)$.

\begin{tabular}{|l|l|}
\hline Mental Retardasyon & $254(\% 42.3)$ \\
\hline Epilepsi & $137(\% 22.8)$ \\
\hline $\begin{array}{l}\text { Felç } \\
\text { Dikkat Eksikliği Hiperaktivite } \\
\text { Bozukluğu }\end{array}$ & $194(\% 32.3)$ \\
\hline Hafıza bozukluğu & $111(\% 18.5)$ \\
\hline $\begin{array}{l}\text { Öğrenme güçlüğü } \\
\text { Hasar bırakır fakat ne olduğuna dair } \\
\text { fikrim yok }\end{array}$ & $122(\% 20.3)$ \\
\hline
\end{tabular}

katıııcı (\% 63.6) FK'nın ne olduğunu bildiğini iddia etmelerine rağmen tanımlaması istendiğinde ise 101 (\%16.8) katıımcının doğru olarak ifade ettikleri saptandı. Doğru ifadede bulunan 101 kişinin bilgi edindikleri kaynaklar ise etraftan duydukları (\%44.6), sağlık çalışanları (\%40.6), internet (\%40.6), kendi deneyimi (\%34.7), televizyon (\%15.8), kitap (\%10.9), gazete (\%7.9)'du.

Üç yüz altmış dokuz (\%61.5) katılımcıya göre FK tekrar edebilir, 13 (\%2.2) katıımcıya göre tekrar etmezdi; 218 (\%36.8) katılımcının ise FK'un tekrar edip etmeyeceği hakkında bir fikri yoktu. FK geçiren çocuğa nasıl müdahale edeceğini bildiğini söyleyen 337 (\%56.2) kişinin ancak 31'inin (\%5.1) bilgisi doğruydu. Katıımcıların FK geçiren çocuğa nasıl müdahale edileceği konusunda çoklu olarak seçtikleri bilgi kaynakları Tablo III'te verildi.

Eğitim ve gelir düzeyi arttıkça $F K(p=0.001 / p=0.006)$ ve FK'a nasıl müdahale edileceği hakkındaki bilgi de $\operatorname{artmaktadır}(\mathrm{p}=0.005 /$ $\mathrm{p}=0.013) .227$ (\%37.8) katılımcının bir yakını FK geçirmişti, 211 (\%35.2) katılımcı ise bizzat FK'a tanıklık etmişti. Tanıklık edenlerin \%80'i kaygılanmış, \%20'si kaygılanmamıştı. FK'a tanıklık etmek ve müdahale konusundaki bilginin doğruluğu arasında pozitif korelasyon mevcuttu ( $p=0.000)$. Katılımcının bir yakını FK geçirdi ise nasıl müdahale edeceği ile ilgili bilgisi artmış olarak bulundu ( $p=0.017)$.

Febril konvülziyonun tanımı hakkında doğru bilgi sahibi olma ile çocuk sahibi olma, FK'a tanıklık etme, kaygı, yakınının FK geçirmesi arasında ilişki bulunamad. Yine FK'a müdahale hakkında doğru bilgi sahibi olma ile çocuk sahibi olma, kaygı arasında ilişki bulunamadı. 449 (\%74.8) katılımcı FK'un kalıcı bir hasar bıraktığını düşünüyordu, 41 (\%6.8) katıımcıya göre FK kalıcı bir hasar bırakmıyordu, 110 katılımcının (\%18.4) ise bu konuda bir fikri yoktu. FK kalıcı hasar bırakır diyen katılımcıların 'hangi kalıcı hasarı bırakır' sorusuna çoklu seçim yanıtları Tablo IV'te özetlenmiştir. 
Eğitim düzeyi arttıkça kalıı hasar bıraktığı yönündeki düşünce azalmakta olup ( $p=0.041)$, katıımcının yakını FK geçirdi ise bu düşünce belirgin olarak artmaktadır ( $p=0001$ ). FK'un kalıc hasar bırakıp bırakmaması ile gelir düzeyi, çocuk sahibi olma, FK'a tanık olma, kaygılanma arasında bir korelasyon bulunmadı.

\section{TARTIŞMA}

Febril konvülziyon sağlık çalışanları için sık karşılaşılan benign bir klinik tablo olsa da ilk defa şahit olan hasta yakınları için çok ürkütücü olabilir. Yapılan birçok çalışma ebeveynlerin FK hakkında bilgilerinin zayıf olduğunu göstermiştir (6-8).

Çalışmamızda katıımcıların çoğunluğunu çocuklara ülkemizde genellikle primer bakımı sağlayan orta yaşı kadınlar oluşturmaktaydı. Katılımcıların eğitim seviyelerinin yarıdan fazlasının lise / üniversite olması merkezimizin başkentte orta gelir düzeyi düzeyli bir semtte bulunuyor olmasından ötürü olabilir.

Katılımcıların \%63.6'i febril konvülziyon hakkında bilgi sahibi olduğunu düşünse de ancak \%16.8'inin febril konvülziyon tanımı doğruydu. Benzer şekilde febril konvülziyon esnasında nasıl müdahale edilmesi gerektiğini katımcıların \%56.2'si bildiğini düşünse de bu grubun ancak onda biri doğru bilgiye sahipti. FK esnasında soğuk suya sokma, ağzına elini sokma, sarsma gibi yanlış uygulamaların olduğu görüldü. Her iki soruya doğru cevap verenlerin öncelikli bilgi kaynakları sağlık çalışanları, etraftan duydukları ve internetti. Televizyon, kitap ve gazete ise en az faydalanmış olan kaynaklardı. Bu iletişim kanalları hasta yakınlarını bilgilendirmek için daha etkin kullanılması faydalı olabilir.

Clericetti ve ark. (9) yakın zamanda yaptıkları ateş korkusu üzerine bir çalışmada, 76 yayını irdelemiş; düşük eğitimsosyoekonomik düzey, etnisite ve FK öyküsünü ebeveynlerdeki ateş korkusu ile ilişkilendirmiştir. Ateş korkusunun global bir durum olduğu ve sağlık çalışanlarını ateși gereksiz tedaviye ittiğini vurgulamaktadır. Görüldüğü üzere ateş korkusu gelişmesinde febril konvülziyonun da payı vardır. Birçok çalışma çocuklarının FK geçirdiğine şahit olan ebeveynlerin çoğunun çocuklarının öleceğini düşündüğünü göstermektedir (6-8). Bilgi eksikliği, çaresizlik duygusuna çocuklarının boğulacağı, epileptik olacağı, beyin hasarı kalacağı gibi yanlış yargllar da eklenir (10). FK'a şahit olan ebeveynlerde uyku bozukluğu, dispepsi gibi somatik sorunlar da görülebilir (5). Ok Ju ve ark. (11) yaptığı bir çalışmada çocuğu FK geçiren annelerde anksiyete nedeninin özellikle belirsizlik olduğu bildirilmiştir. Çalışmamızda FK'a tanıklık edenlerin \% 80'i kaygılandığını belirtti.

Hasta yakınları FK'a bizzat tanıklık etti ya da bir yakını FK geçirdi ise müdahale konusundaki bilginin de arttığı saptandı.
Westin ve ark. (12) yaptıkları çalışmada ailelerin bir defa FK deneyimledikten sonra rekürren FK'a müdahale ederken daha iyi hissettiklerini, bunun da kısmen acil serviste bilgilendirilmiş ilişkili olabileceğini ifade etmişlerdir. İngiltere ve İsviçre'de yapılan 2 çalışmada anneler FK öncesi ya da en azından hastaneye başvurunun ilk saatlerinde daha çok bilgilendirmiş olmayı dilemektedirler $(13,14)$.

Daha önce de belirtildiği gibi FK'un genel olarak kalıc bir hasar bırakmadığı düşünülmekte olup sonrasında afebril nöbet görülebileceği ile ilgili görüşler mevcuttur. 666 hastayı kapsayan bir kohort çalışmasında FK geçiren tüm çocuklarda 20 yaşta epilepsi riski \%6 olarak bulunmuștur. FK'un kompleks olması ve nöbetin uzaması risk olarak belirtilmiştir. Fakat bu çalışmada eșlik eden nörogelişimsel sorunları olan hastalar dışlanmamıştır (15). 428 çocuk başka bir prospektif çalışmada illk FK'ları sonrası takip edilmiş, yine \% 6'sında nöbet izlenmiştir (16). Ingiltere'de yapılan toplum bazı geniş prospektif bir kohortta araştırmacılar hastaları minimum 8.4 yı izlemiş ve \%6 hastada epilepsi geliştiği görülmüştür (17). Ülkemizde yapılan bir çalışmada da epilepsi riski \%7.2 olarak bulunmuş, en önemli risk faktörünün de eşlik eden nörogelişimsel anomali olduğu bildirilmiştir (18). Fakat FK uzun vadede mortalite artışı veya gelecekteki akademik başarı, zeka veya davranış üzerindeki olumsuz etkilerle ilişkilendirilmemiştir $(19,20)$.

Bizim çalışmamızda ise katıımcıların \%74.8'i FK'un kalıcı hasar bıraktı̆̆ını düşünmekte olup bu yanlış yargı eğitim düzeyi artıkça azalmaktaydı. Mental retardasyona neden olacağı fikri en yaygın olandı (\%42.7). Katııımıını bir yakını FK geçirdi ise kalıı hasar bıraktığı fikri artmaktaydı. Literatürde çocukları FK nedeni ile hastaneye yatııımış 132 aile sorgulandığında ailelerin \%65.2 si beyin hasarı, \% 54.6'sı epilepsi, \%68.9'si yeni havale ve \% 59.1'i ölümden bahsettiği izlenmiştir (8).

Elbette bu çalışmanın bulguları tüm toplumu yansıtmıyor olabilir fakat hasta yakınlarının FK hakkında az bilgi sahibi olduğu ve sağlık çalışanları tarafindan eğitimi faydalı olacağı düşünülmektedir.

Sonuç olarak, katılımcıların FK hakkındaki bilgi düzeyi belirgin düşük, kaygıları ise yüksektir. Hasta yakınlarının sağık çalışanları tarafından eğitimi faydalı olacaktır.

\section{KAYNAKLAR}

1. Guidelines for epidemiologic studies on epilepsy. Commission on epidemiology and prognosis, international league against epilepsy. Epilepsia 1993;34:592-6.

2. Steering Committee on Quality Improvement and Management, Subcommittee on Febrile Seizures American Academy of Pediatrics. Febrile seizures: clinical practice guideline for the long-term management of the child with simple febrile seizures. Pediatrics 2008;121:1281-6.

3. Mikati MA. Febrile seizures. In: Kliegman RM, Stanton BF, St Geme JW, Schor NF, Behrman RE, editors. Nelson textbook of pediatrics. 19th ed.Philadelphia: Elsevier; 2011. 
4. Whelan H, Harmelink M,Chou E, Sallowm D, Khan N, Patil R, et al. Complex febrile seizures-A systematic review. Dis Mon 2017;63:5-23.

5. Balslev T. Parental reactions to a child's first febrile convulsion: A follow-up investigation. Acta Paediatr Scand 1991;80:446-9.

6. Kolahi AA, Tahmooreszadeh S. First febrile convulsions: inquiry about the knowledge, attitudes and concerns of the patients' mothers. Eur J Pediatr 2009;168:167-71.

7. Sajadi M, Khosravi S. Mothers' Experiences about Febrile Convulsions in Their Children: A Qualitative Study. Int J Community Based Nurs Midwifery 2017;5:284-291.

8. E Tamvaki, E Papathanassoglou, V Matziou. The assessment of knowledge and attitudes of parents of hospitalized children about febrile convulsions: A pilot study. Nosileftiki 2011;50:72-84

9. Clericetti CM, Milani GP, Bianchetti MG, Simonetti GD, Fossali EF. Systematic review finds that fever phobia is a worldwide issue among caregivers and healthcare providers. Acta Paediatr 2019;108:1393-7.

10. Freeman JM. The best medicine for febrile seizures. N Eng J Med 1992;327:1161-3

11. Ju HO, McElmurry BJ, Park CG, McCreary L, Kim M, Kim EJ, et al. Anxiety and uncertainty in Korean mothers of children with febrile convulsion: cross-sectional survey. J Clin Nurs 2011;20:1490-7.

12. Westin E, Sund Levander M. Parent's Experiences of Their Children Suffering Febrile Seizures. J Pediatr Nurs 2018;38:6873.
13. Flury $T$, Aebi $C$, Donati F. Febrile seizures and parental anxiety: does information help? Swiss Med Wkly 2001;131:556-60.

14. Miller $R$, The effect on parents of febrile convulsions. Paediatr Nurs 1996;8:28-31.

15. Annegers JF, Hauser WA, Elveback LR, Kurland LT. The risk of epilepsy following febrile convulsions. Neurology 1979;29:297303.

16. Berg AT, Shinnar S. Unprovoked seizures in children with febrile seizures: short-term outcome. Neurology 1996;47:562-8.

17. MacDonald BK, Johnson AL, Sander JW, Shorvon SD. Febrile convulsions in 220 children-neurological sequelae at 12years follow-up. Eur Neurol 1999;41:179-86.

18. Canpolat M, Per H, Gumus H, Elmali F, Kumandas S. Investigating the prevalence of febrile convulsion in Kayseri, Turkey: An assessment of the risk factors for recurrence of febrile convulsion and for development of epilepsy. Seizure 2018;55:36-47.

19. Smith DK, Sadler KP, Benedum M. Febrile Seizures: Risks, Evaluation, and Prognosis. Am Fam Physician 2019;99:445-50.

20. Chang YC, Guo NW, Huang CC, Wang ST, Tsai JJ. Neurocognitive attention and behavior outcome of school-age children with a history of febrile convulsions: a population study. Epilepsia 2000;41:412-20. 